\title{
Effect of Deep Relaxation on Heart Rate Variability in Sedentary Females
}

\author{
Monzur-E- Fatema', Noorzahan Begum ${ }^{2}$, Sultana Ferdousi ${ }^{3}$
}

\begin{abstract}
Background: Sedentary lifestyle is associated with low heart rate variability (HRV). Deep Relaxation Technique (DRT) increase HRV which reduces the risk of coronary heart diseases. Objectives: To assess HRV after practicing DRT to find out it's effect on cardiac autonomic nerve function in sedentary subjects. Methods: This cross sectional study was carried out in the Department of Physiology, Bangabandhu Sheikh Mujib Medical University between July 2012 and June 2013 on 30 apparently healthy sedentary females aged 25-35 years (study) who were practicing DRT with 3 months duration. For comparison, age and BMI matched 30 apparently healthy sedentary females who had no experience of relaxation technique (control) were also studied. Both groups were selected from the sedentary housewives by personal contact. The study subjects were the participants in a private yoga center in Dhaka. HRV was assessed by a Polygraph. Statistical analysis was done by Independent Sample ttest. Results: Resting mean heart rate $(\mathrm{p}<0.001)$ was significantly lower and mean R-R interval and SDNN ( $p<0.001)$, RMSSD $(p<0.05)$ were significantly higher in the relaxation group than the control group. Conclusion: DRT improves cardiac autonomic nerve function with parasympathetic dominance in sedentary females.
\end{abstract}

Key words: HRV, Sedentary females, Deep relaxation technique.

Bangladesh Soc Physiol. 2013, December; 8(2): 65-69 For Authors Affiliation, see end of text.

http://www.banglajol.info/index.php/JBSP

\section{Introduction}

$\mathbf{R}$

elaxation is a positively perceived state or response in which a person feels relief of tension or strain. ${ }^{1}$ European Society of Cardiology defined relaxation as to induce a reduction of tension within individual without using external means. ${ }^{2}$

Relaxation techniques are useful in stress management. It can help to cope with various health problems related to stress, such as cancer and pain. ${ }^{3}$ It can also significantly improve angina pectoris, cardiac arrhythmias, hypertension, diabetes, bronchial asthma, anxiety, insomnia, rheumatoid arthritis. ${ }^{4}$

Received July 2013; $\quad$ Accepted December 2013
Most common forms of relaxation techniques include progressive muscle relaxation, meditation, yoga, visualization and deep relaxation technique (DRT) which in the form of meditation induces quiet state in mind. ${ }^{3,5,6}$ Among the different yoga based relaxation techniques, effects of deep relaxation technique (DRT), cyclic meditation (CM) and different forms of meditation have been studied by several investigators. ${ }^{5}$

European Society of Cardiology reported that relaxation technique had been used in cardiac rehabilitation since $1970^{2}$. A study reported recovery of seriously ill cardiac patients through relaxation and dietary modification. ${ }^{7}$ 
Relaxation practice has earned popularity in Bangladesh. Good cardiac health and multisystem benefits among the people practicing relaxation technique has been recognized. .,7-9 $^{-1}$

Several researchers investigated the effect of relaxation response on cardiac autonomic nerve function by assessing heart rate variability (HRV).It is a non invasive procedure to quantify the influence of autonomic nervous system on heart. $^{10}$

HRV analysis is a worldwide accepted technique to measure variations of instantaneous heart rate as well as the R-R intervals. ${ }^{10}$ Common time domain measures include mean NN (RR) interval, mean heart rate (HR) standard deviation of $\mathrm{NN}$ interval (SDNN) and square root of mean squared differences of successive NN intervals (RMSSD). ${ }^{10}$ Theses measures reflect cardiac parasympathetic modulation. Research evidences reported that relaxation may induce an increase in parasympathetic outflow along with a decrease in sympathetic activity. It is associated with higher heart rate variability (HRV) with reduced risk of coronary heart diseases. ${ }^{2,9}$

Significant reduction in resting HR in patients with ischemic heart disease as well as healthy volunteers and higher RMSSD in healthy females after practicing relaxation technique has been reported. ${ }^{2,11-13}$ Again, no change in HR after relaxation technique in healthy volunteers after practicing yoga for 3-15 years was also reported ${ }^{14}$.Sedentary lifestyle has been found to be associated with decrement of cardiac parasympathetic activity. ${ }^{13-16}$

In Bangladesh, the effect of sedentary life style on cardiac autonomic nerve function was investigated by comparing HRV between sedentary adolescents and adolescent athlets and also between adult heavy workers and adult sedentary people. ${ }^{13,-15,17}$ But the effect of relaxation technique on $\mathrm{HRV}$ in sedentary subjects was not investigated. Assessment of the effect of relaxation technique on these cardiac autonomic nerve function parameters in sedentary subjects may be helpful as a preventive measure against the risk of unfavorable cardiac health.

Therefore, this study has been designed to assess the effects of relaxation technique on cardiac autonomic nerve function activity by analyzing the HRV in sedentary females in order to find out its role in reducing cardiovascular morbidity and mortality in this group of people.

\section{Methods}

This cross-sectional study was carried out in the department of physiology of Bangabandhu Sheikh Mujib Medical University between July 2012 to June 2013. Institutional review board approved the protocol. 30 apparently healthy sedentary females, aged from 25-35 years who were experienced with DRT for 3 months were selected as study group (Group B) and 30 age and BMI matched sedentary females previously never exposed to relaxation technique were selected as control group (Group A). Control subjects were selected from the sedentary housewives in and study group from the sedentary housewives with previous experience of practicing DRT for 3 months from a private yoga center in Dhaka city. Any subject suffering from systemic diseases, obesity, psychic disorder and drug users specially drug affecting nervous system were excluded from the study. The aim and objectives of the study were

explained and they were encouraged for voluntary participation. A written informed consent was taken from each subject. A thorough clinical examination was done and personal history of all subjects were recorded in a prefixed data schedule. The subject was also advised to avoid tea or coffee at breakfast and to attend at the Autonomic Nerve Function Test Laboratory of the Department of Physiology of BSMMU between 9:00 am to 11:00 am on the day of examination. Then the subject was kept under complete bed rest in supine position for 20 
minutes in a cool and calm environment at the laboratory.

During this test period, she was restricted to talk, eat, drink, any physical or mental activity and even sleep. Then a 5 minutes ECG recording was taken in resting supine position and the time domain measures of the HRV were obtained by a digital polyrite. All data were expressed as mean \pm SD. Statistical analysis was performed by using SPSS for windows version 16.0. Independent Sample t-test compares the mean of time domain measures between groups. $\mathrm{P}$ value $<0.05$ was accepted as level of significance.

\section{Results}

Subjects of two groups were matched for age and BMI but the resting pulse rate $(\mathrm{p}<0.001)$, $\operatorname{DBP}(\mathrm{p}<0.01)$ and SBP $(\mathrm{p}<0.01)$ were significantly lower in group B than those of group A.(Table I).

Table I : Mean \pm SD of General characteristics in different groups $(\mathrm{n}=60)$

\begin{tabular}{lccc}
\hline Parameters & $\begin{array}{c}\text { Group A } \\
(\mathrm{n}=30)\end{array}$ & $\begin{array}{c}\text { Group B } \\
(\mathrm{n}=30)\end{array}$ & p value \\
\hline Age & $\begin{array}{c}29.97 \pm 3.02 \\
(25-35)\end{array}$ & $\begin{array}{c}29.00 \pm 3.05 \\
(25-35)\end{array}$ & $>0.05$ \\
& $21.75 \pm 1.87$ & $21.10 \pm 1.64$ & $>0.05$ \\
BMI & $(19.05-24.90)$ & $(19.04-24.70)$ & \\
& $77.47 \pm 6.78$ & $71.90 \pm 5.60$ & $<0.01$ \\
Pulse & $(68-88)$ & $(65-86)$ & \\
(bpm) & $116.30 \pm 2.65$ & $113.27 \pm 3.70$ & $<0.01$ \\
SBP & $(110-118)$ & $(105-118)$ & \\
(mm of Hg) & & \\
DBP & $75.30 \pm 3.39$ & $72.20 \pm 4.16$ & $<0.01$ \\
(mm of Hg) & $(65-78)$ & $(68-78)$ & \\
\hline
\end{tabular}

Figures in parentheses indicate ranges. $\mathrm{SBP}=$ Systolic blood pressure, $\mathrm{DBP}=$ Diastolic blood pressure $\mathrm{BMI}=$ Body Mass Index, Group A=Non relaxation group, Group B= Relaxation group
The mean values of heart rate $(\mathrm{p}<0.001)$ was significantly lower whereas SDNN $(\mathrm{p}<0.001)$ and RMSSD $(p<0.05)$ and R-R interval $(p<0.001)$ were significantly higher in group $B$ than those of group A. (Table II).

Table II: Mean \pm SD of Time domain measures of HRV in different groups $(n=60)$

\begin{tabular}{lccc}
\hline Parameters & $\begin{array}{c}\text { Group A } \\
(\mathrm{n}=30)\end{array}$ & $\begin{array}{c}\text { Group B } \\
(\mathrm{n}=30)\end{array}$ & p value \\
\hline MeanR-R & $0.65 \pm 0.05$ & $0.83 \pm 0.07$ & $<0.001$ \\
interval (Sec) $(0.56-0.73)$ & $(0.71-0.93)$ & \\
Mean HR & $79.60 \pm 5.96$ & $72.67 \pm 4.97$ & $<0.001$ \\
(bpm) & $(70-88)$ & $(65-84)$ & \\
SDNN & $37.94 \pm 8.65$ & $54.61 \pm 8.58$ & $<0.001$ \\
$(\mathrm{~ms})$ & $(26.91-57.88)$ & $(43.25-74.02)$ & \\
RMSSD45.05 \pm 23.22 & $58.14 \pm 19.70$ & $<0.05$ \\
$(\mathrm{~ms})$ & $(19.78-105.57)$ & $(20.13-95.56)$ & \\
\hline
\end{tabular}

$\mathrm{R}-\mathrm{R}=$ Interval between successive QRS complex, Sec $=$ Second, $\mathrm{HR}=$ Heart rate, $\mathrm{SDNN}=$ Standard deviation of $\mathrm{NN}$ intervals, $\mathrm{ms}=$ millisecond, $\mathrm{RMSSD}=$ Square root of mean squared differences between adjacent $\mathrm{NN}$ intervals

\section{Discussion}

The present study assessed mean R-R interval, mean heart rate, SDNN and RMSSD which reflect cardiac vagal activity in sedentary females to observe the influence of practicing DRT on cardiac autonomic nerve function in sedentary life style. ${ }^{10}$ In this study, higher mean R-R interval, SDNN and mean RMSSD and lower heart rate were found in the sedentary females who practiced DRT than those of the non relaxation group. There was no published data available to compare these findings.

In this study, the values of HRV measures in the sedentary females practicing DRT suggested increased cardiac vagal modulation in the subjects of the present series. Though the exact cause of this change under DRT is not clear but 
literature proposed, increased beta receptor responsiveness, ${ }^{18}$ activation of the neural network ${ }^{4,5,19-24}$ may be responsible for the changes in cardiac autonomic nervous activity associated with deep relaxation technique, but it is difficult to comment on this, as the above mentioned parameters were not possible to measure in the subjects of the present series. Therefore, the exact mechanism involved with increased cardiac parasympathetic activity in deep relaxation technique practitioners cannot be revealed from this type of study. From the above feature it is apparent that DRT may play an important role by modifying cardiac autonomic nervous activity towards parasympathetic dominance to maintain cardiovascular health and thus to prevent cardiac morbidity and mortality.

\section{Conclusion}

From this study it can be concluded that cardiac vagal activity may be increased in subjects who practice deep relaxation technique. Therefore, deep relaxation technique may be beneficial to maintain cardiac health and in preventing the occurrence of cardiovascular diseases in this group of females.

\section{Authors affiliation}

1. *Monzur-E-Fatema, Assistant Professor, Department of Physiology, City Medical College, Gazipur. Email:dr.zoti@gmail.com.

2. Noorzahan Begum, Professor, Department of Physiology, Bangabandhu Sheikh Mujib Medical University (BSMMU), Bangladesh. Email:noor zahanbeg@yahoo.com.

3. Sultana Ferdousi, Associate professor, Department of Physiology, Bangabandhu Sheikh Mujib Medical University (BSMMU), Bangladesh. Email: sferdousiratna@gmail.com.

\section{References}

1. Htut $\mathrm{T}$. The effects of meditation on the body. [Internet]. 1999 [cited 2012 Sep 11].Available from: www.thisismyanmar.com/nibbana/ tinhtut.htm.

2. Dixhoorn JV, White A. Relaxation therapy for rehabilitation and prevention in ischemic heart disease: A systematic review and meta analysis. Eur J Cardiovasc Prev Rehabil. 2005;12:193-202.
3. Relaxation techniques: try these steps to reduce stress. [Internet].[cited 2012 Oct 3]. Available from: Mayoclinic.com.

4. Benson H, Klipper MZ. The Relaxation Response. USA: Harper Collins; 1975.

5. Cohen DL, Wintering N, Tolles V, Townsend RR, Farrar JT, Galantino ML, Newberg AB. Cerebral blood flow effects of yoga training: Preliminary evaluation of 4 cases. The Journal of Alternative and Complementary Medicine. 2009;15(1): 9-14.

6. Subramanya T, Telles S. A review of scientific studies on cyclic meditation. Int J Yoga. 2009; 2(2): 46-48.

7. Ornish D. Reversing Heart Disease. USA: Ballantine Books; 1990.

8. Wenneberg SR, Schneider RH, Walton KG, Maclean CR, Levitsky DK, Salerno JW, Wallace RK, Mandarino JV, Rainforth MV, Waziri R. A controlled study of the effects of the Transcendental Meditation program on cardiovascular reactivity and ambulatory blood pressure. Int J Neurosci. 1997;89(1-2):15-28.

9. Paul-Labrador M, Polk D, Dwyer JH, Velasquez I, Nidich S, Rainforth M, Schneider R, Merz NB. Effects of a randomized controlled trial of Transcendental meditation on components of metabolic syndrome in subjects with coronary heart disease. Arch Intern Med. 2006;166: 1218-1224.

10. Task Force of the European Society of Cardiology and the North American Society of Spacing and.Electrophysiology. Heart Rate Variability: standards of measurement, physiological interpretation and clinical use. Circulation.1996; 93:1043-1065.

11. Sarang PS, Telles S. Effect of two yoga based relaxation techniques on HRV. International Journal of Stress Management. 2006;13 (4):460-475.

12. Vempati RP, Telles S. Yoga based guided relaxation reduces sympathetic activity in subjects based on baseline levels. Psychol Rep. 2002; 90(2): 487-94.

13. An H, Kulkarni R, Nagarathna R, Nagendra HR. Measures of HRV in women following a meditation technique. Int J Yoga. 2010; 3(1): 6-9.

14. Peng CK, Henry IC, Mietus JE, Hausdorff JM, Khalsa G, Benson H, Goldberger AL. Heart rate dynamics during three forms of meditation. Int $\mathrm{J}$ of Cardiol. 2004; 95: 19-27. 
15. Mithun S. Comparative study of cardiac autonomic nerve function status by heart rate variability between sedentary and heavy workers. [Thesis][Dhaka (Bangladesh)]: BSMMU. 2009.

16. Mischel NA, Mueller PJ. (In)activity-dependent alterations in resting and reflex control of splanchnic sympathetic nerve activity. J Appl Physiol. 2011; 111: 1854-1862.

17. Alom M. Study on heart rate variability in adolescent male athlete. [Thesis] [Dhaka (Bangladesh)]: BSMMU. 2008.

18. Mills PG, Schneider RH, Hill D, Walton KG, Wallace RK. Beta-adrenergic receptor sensitivity in subjects practicing transcendental meditation. J Psychosom Res. 1990; 34(1): 29-33.

19. Lazar SW, Bush G, Gollub RL, Fricchione GL, Khalsa G, Benson H. Functional brain mapping of the relaxation response and meditation. NeuroReport. 2000; 11:1581-1585.
20. Newberg AB, Iversen $J$. The neural basis of the complex mental task of meditation: neurotransmitter and neurochemical considerations. Medical Hypotheses. 2003; 61(2): 282-291.

21. Davidson RJ, Kabat-Zinn J, Schumacher J, Rosenkranz M, Muller D, Santorelli SF, Urbanowski F, Harrington A, Bonus K, Sheridan JF. Alterations in brain and immune function produced by mindfulness meditation. Psychosomatic Medicine. 2003; 65: 564-570.

22. Conrad A, Roth WT. Muscle relaxation therapy for anxiety disorders: it works but how? Journal of Anxiety Disorders. 2007; 21: 243-264.

23. Tang YY, Ma Y, Fan Y, Feng H, Wang J, Feng S, Lu Q, Hu B, Lin Y, Li J, Zhang Y, Wang Y, Zhou L, Fan M. Central and autonomic nervous system interaction is altered by short- term meditation. PNAS. 2009; 106 (22): 8865-8870.

24. Dooley C. The impact of meditative practices on Physiology and Neurology: A review of the literature. Scientia Discipulorum. 2009; 4: 35-59. 